Cite this: Phys. Chem. Chem. Phys., 2012, 14, 9350-9358

\title{
Carbon monoxide adsorption on neutral and cationic vanadium doped gold clusters $\dagger$
}

\author{
Hai Thuy Le, Sandra M. Lang, $\ddagger$ Jorg De Haeck, Peter Lievens* and \\ Ewald Janssens
}

Received 31st October 2011, Accepted 9th January 2012

DOI: $10.1039 / \mathrm{c} 2 \mathrm{cp} 23427 \mathrm{k}$

The effect of a single vanadium dopant atom on the reactivity of small gold clusters is studied in the gas phase. In particular we investigated carbon monoxide adsorption on vanadium doped gold clusters using a low-pressure collision cell. Employing this technique the reactivity of both neutral and cationic clusters was studied under the same experimental conditions. Analysis of the kinetic data as a function of the pressure in the reaction cell shows that the reaction mechanism is composed of a fast adsorption and a delayed dissociation reaction. It is demonstrated that the reactivity of positively charged $\mathrm{Au}_{n} \mathrm{~V}_{m}{ }^{+}(n=8-30, m=0-3)$ is greatly enhanced as compared to the corresponding neutral species and that dissociation rates decrease with decreasing temperatures. While the overall magnitude of the reactivity does not change upon doping with vanadium clusters, the size dependence is significantly affected. The neutral singly vanadium doped gold clusters show a sudden drop after size $\mathrm{Au}_{13} \mathrm{~V}$, followed by a smooth increase, in contrast to the extended odd-even staggering for bare gold clusters. This difference can be explained by changes in the electronic structure of the clusters, related to the partly filled $3 \mathrm{~d}$ shell of the vanadium dopant atom.

\section{Introduction}

Gold is one of the most unique elements in the periodic table. The inertness of bulk gold makes it a noble metal and hence was regarded as catalytically inactive for a long time. In contrast, when the dimensions of a gold particle are reduced to the nanometre scale, the particle shows a highly selective catalytic performance. This turns gold into one of the most promising elements for catalytic industry. ${ }^{1}$ Although nanometre sized gold particles can catalyze many reactions, such as $\mathrm{NO}_{x}$ reduction (DeNOx), partial oxidation of hydrocarbons, methanol synthesis, and the water-gas shift, ${ }^{2-8}$ the major focus of most fundamental studies has been on the catalytic $\mathrm{CO}$ oxidation. ${ }^{9}$ The $\mathrm{CO}$ adsorption onto gold clusters is one of the two elementary steps of the CO combustion and attracted a lot of interest from both experimentalists ${ }^{3,10-17}$ and theoreticians, ${ }^{18-20}$ who investigated the dependence of the $\mathrm{CO}$ adsorption on the size and charge state of the clusters.

Earlier studies demonstrated that the presence of a single doped atom in a gold cluster has a strong influence on its

Laboratory of Solid State Physics and Magnetism, Department of Physics and Astronomy, KU Leuven, B-3001 Leuven, Belgium. E-mail:peter.lievens@fys.kuleuven.be

$\dagger$ Paper submitted on the occasion of the 65th birthday of professor Ludger Wöste.

$\ddagger$ Present address: Institute of Surface Chemistry and Catalysis, University of Ulm, 89069 Ulm, Germany. geometric and electronic structure, ${ }^{21-24}$ and consequently changes the physical and chemical properties. For example, it was found that when being supported on well-characterized $\mathrm{MgO}(100)$ thin films, $\mathrm{Au}_{3} \mathrm{Sr}$ reacts with $\mathrm{O}_{2}$ and $\mathrm{CO}$ but $\mathrm{Au}_{4}$ does not. ${ }^{25}$ Tielens et al. $^{26}$ performed a DFT study and revealed that $\mathrm{O}_{2}$ adsorption onto a gold nanopyramid is easier when the gold atom on top of the pyramid is substituted by a platinum atom. The work of Koszinowski and co-workers ${ }^{27}$ showed that the reactivity of small bimetallic $\mathrm{Au}_{n} \mathrm{Pt}_{m}{ }^{+}$clusters towards $\mathrm{O}_{2}$ and $\mathrm{CH}_{4}$ is sensitive to the $\mathrm{Pt}$ fraction. In principle, one can think of improving the catalytic properties of gold clusters by tuning the electronic structure, which can effectively be done by doping the cluster. Many studies on the $\mathrm{CO}$ combustion catalyzed by doped gold clusters considered transition metal $\left(\mathrm{Au}_{n} \mathrm{Y},{ }^{28} \mathrm{Au}_{n} X\right.$ with $X=\mathrm{Pd}, \mathrm{Pt},{ }^{29,30}$ $\mathrm{Au}_{12} \mathrm{~W},{ }^{31,32}$ and $\left.\mathrm{Au}_{12} \mathrm{~V}^{-33}\right)$, coinage metal $\left(\mathrm{Au}_{n} \mathrm{Ag}_{m}{ }^{0,+,-}\right.$ and $\left.\mathrm{Au}_{n} \mathrm{Cu}_{m}{ }^{+}\right),{ }^{13,29,34-42}$ or alkali metal $\left(\mathrm{Au}_{n} X\right.$ with $X=\mathrm{H}$, $\mathrm{Li}, \mathrm{Na}^{43}$ ) dopant atoms.

A great amount of research has been performed to investigate the reactivity of metal clusters in the gas-phase. Based on the type of reactor, three techniques can be distinguished: (i) reactions in ion traps, (ii) flow-tube reactions, and (iii) collision cell reactions. Wöste, Bernhardt and co-workers have been using a home-built radio frequency (rf) octupole ion trap to study the reactivity of few-atom gold and silver clusters as well as silver-gold alloys towards small molecules such as $\mathrm{CO}, \mathrm{NO}$, $\mathrm{O}_{2}$, and $\mathrm{CH}_{4} \cdot{ }^{12,37,39,44-48} \mathrm{An}$ ion cyclotron resonance (ICR) trap 
has been used by Kappes and co-workers to investigate the kinetics of the interaction between cationic gold and binary gold-silver clusters with CO. ${ }^{40,41,49}$ In ion traps the reaction time is a controlled parameter allowing measurements of the reaction kinetics. Flow-tube reactors were used by Wallace and Whetten for investigating the reactivity of cationic and anionic gold clusters. ${ }^{3,14}$ The third technique that is used to study the gas phase cluster's reactivity is based on low-pressure collision cells. Kinetic data are measured as a function of the pressure in the cell. The reaction time, which is based on the drift time through the cell, is roughly constant. The advantage of this technique is that it can be applied for neutral species. The main drawback, however, is the absence of a heat bath. Therefore, the formation energy following adsorption of the molecule must be stored in the product and hence there is a high possibility that the product dissociates again. ${ }^{16,50}$ Because of this, the sticking probability derived when applying pseudo-first order kinetics should be interpreted as the net result of a forward adsorption reaction and a concurrent and/or subsequent backward desorption reaction. ${ }^{16}$

In this article, we report on the $\mathrm{CO}$ adsorption onto neutral and cationic $\mathrm{Au}_{n} \mathrm{~V}_{m}{ }^{0,+}$ clusters $(n=8-30, m=1-3)$. The experimental method is described in Section 2. In Section 3, the kinetic data are analyzed and the reaction mechanism for the cluster-CO interaction is discussed, showing the importance of the delayed CO desorption. Results on the reactivity of bare cationic $\mathrm{Au}_{n}{ }^{+}$clusters observed in our experiment will be compared with measurements done in an ion trap. ${ }^{49}$ Finally, the reactivity of the neutral and cationic vanadium doped gold clusters will be presented and the size, charge state, and composition dependence of the CO-reactivity are discussed.

\section{Experimental method}

Vanadium doped gold $\mathrm{Au}_{n} \mathrm{~V}_{m}{ }^{0,+}$ clusters are produced in a dualtarget dual-laser vaporization source. ${ }^{51}$ Following vaporization, the plasma containing gold and vanadium atoms are entrained in a short pulse of helium carrier gas and the expansion through a condensation channel initiates cluster formation. Source parameters such as carrier gas pressure, laser energies, and vaporization times are optimized for maximal intensities for singly, doubly, and triply doped gold clusters, $\mathrm{Au}_{n} \mathrm{~V}_{1-3}{ }^{0,+}$. Some clusters with a higher amount of vanadium, $\mathrm{Au}_{n} \mathrm{~V}_{4-7}{ }^{0,+}$, also are produced. The cluster source is cooled to temperatures down to $124 \mathrm{~K}$ using a combination of liquid nitrogen cooling and resistive heating. It is further assumed that the initial (i.e., before reaction) temperature of the clusters can be approximated by the temperature of the cluster source and that the temperature of the $\mathrm{CO}$ reaction gas is equal to room temperature.

To study the attachment of small inorganic molecules to neutral and/or cationic bimetallic clusters in the gas phase, a reaction cell was implemented between our binary cluster source and a reflectron time-of-flight (RTOF) mass spectrometer with mass resolution $M / \Delta M=600$. Fig. 1 gives a schematic overview of the adsorption experiments using a low-pressure collision cell to measure the cluster reactivity. Between the cluster source and the ion extraction of the RTOF, the clusters are exposed to the reactive gas. The reaction cell is constructed on the basis of a design by Andersson et al., ${ }^{52}$ and consists of a hollow cylinder

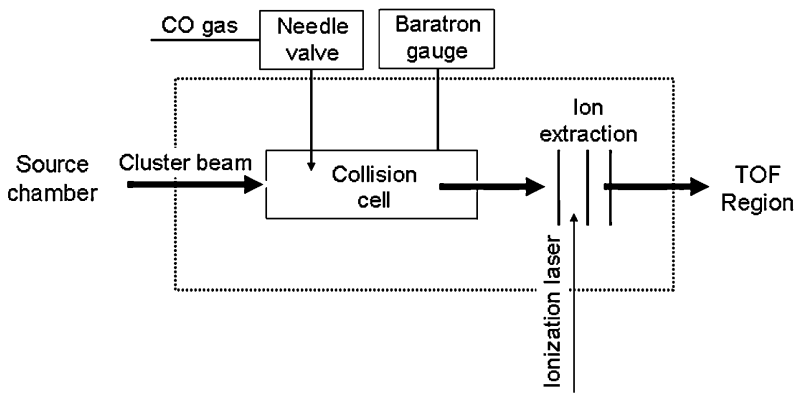

Fig. 1 Schematic overview of the $\mathrm{CO}$ adsorption measurements using a low-pressure collision cell.

with a length of $60 \mathrm{~mm}$ and $6 \mathrm{~mm}$ inner diameter. The reactive gas is introduced by a needle valve and the pressure is measured by a capacitance gauge (MKS Baratron Type 627B). Front and back panels of the reaction cell have $2 \mathrm{~mm}$ and $2.2 \mathrm{~mm}$ apertures, respectively, and ensure a high pressure ratio $\left(>10^{3}\right)$ between the reaction cell and the surrounding chamber, which reduces collisions between the clusters and gas molecules outside the cell.

In the low-pressure collision reaction cell technique, the reaction time is the passage time of the cluster through the reaction cell and it is fixed by the dimensions of the experimental setup. Thus, in order to study the kinetics of the reaction, the pressure of the reactive gas is varied. Details are given in Section 3.1. In the current experiments, the $\mathrm{CO}$ pressure in the reaction cell is varied in the $0-3.5 \times 10^{-3}$ mbar range.

Using hard sphere cross sections, the number of collisions experienced by the clusters during their passage through the cell is estimated to be smaller than five on average. The reactivity of the clusters is thus measured under few collision conditions. Higher pressures are avoided to prevent signal loss due to deflection of the clusters away from the central beam by collisions with the reaction gas.

In order to study the reactivity of the neutral clusters, the charged particles are electrostatically deflected out of the beam. After passage through the reaction cell, the neutral clusters are ionized using an $F_{2}$ excimer laser $(7.89 \mathrm{eV})$ giving the ability to detect the reaction products. The photon energy of $7.89 \mathrm{eV}$ is high enough to ionize neutral bare $\mathrm{Au}_{n}$ clusters for $n \geq 9$. Since the vanadium atom has a lower ionization energy than that of the gold atom, doping gold clusters with vanadium is assumed not to enhance the ionization energy of the clusters.

The ionization laser was kept at low fluence to minimize photoinduced cluster fragmentation. Once ionized, the clusters are extracted by an electrostatic field into the RTOF. To investigate cationic clusters the extraction voltages are pulsed by two fast high voltage switches (Behlke) and no ionization laser is used.

\section{Data evaluation}

The reaction rates are derived from mass spectra recorded at different $\mathrm{CO}$ pressures in the reaction cell. Fig. 2 shows mass spectra of vanadium doped gold clusters in the size range $n=11-20$ : the upper and the middle panels correspond to neutral $\mathrm{Au}_{n} \mathrm{~V}$ clusters, without and with $\mathrm{CO}$, respectively; 


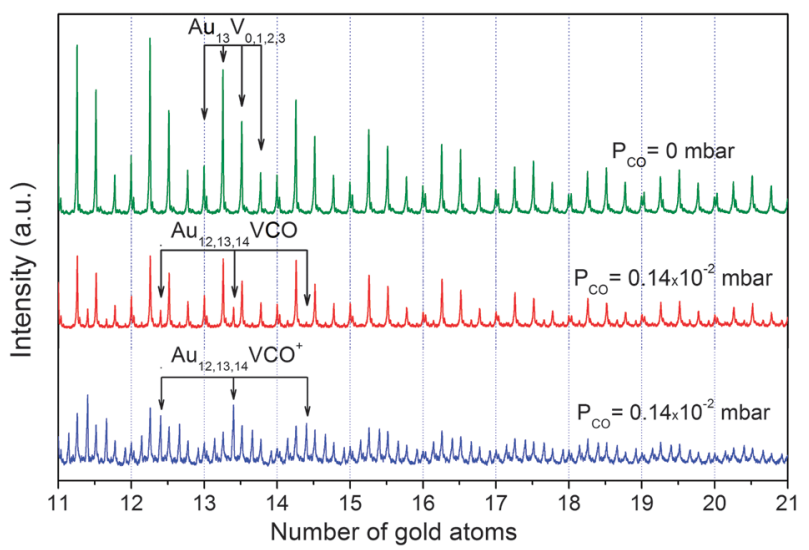

Fig. 2 Mass abundance spectra of $\mathrm{Au}_{n} \mathrm{~V}_{m}{ }^{0,+}(n=11-20, m=0-3)$ clusters produced at a source temperature of $168 \mathrm{~K}$. Spectra of neutral $\mathrm{Au}_{n} \mathrm{~V}_{m}$ clusters without and with $\mathrm{CO}$ reaction gas in the collision cell are shown in the upper and middle panels, respectively; cationic $\mathrm{Au}_{n} \mathrm{~V}_{m}{ }^{+}$cluster with $\mathrm{CO}$ in the lower panel.

the lower panel corresponds to the cationic $\mathrm{Au}_{n} \mathrm{~V}^{+}$clusters with $\mathrm{CO}$. Without $\mathrm{CO}$ in the reaction cell, only the bare clusters are observed. Once $\mathrm{CO}$ gas is introduced into the reaction cell, cluster-CO complexes appear, however, the total signal intensity decreases due to elastic scattering of the neutral clusters at the $\mathrm{CO}$ molecules, deviating them from the molecular beam. At the same $\mathrm{CO}$ pressure and cluster temperature, the relative intensity of $\mathrm{Au}_{n} \mathrm{~V}_{m} \mathrm{CO}^{0,+}$ to $\mathrm{Au}_{n} \mathrm{~V}_{m}{ }^{0,+}$ is obviously higher for the cationic clusters than for the neutral ones, indicating that the cationic $\mathrm{Au}_{n} \mathrm{~V}_{m}{ }^{+}$are more reactive than the corresponding neutral clusters. In the current experiment, only complexes with one $\mathrm{CO}$ molecule attached are observed.

The most simple reaction mechanisms that can explain the presence of $\mathrm{Au}_{n} \mathrm{~V}_{m} \mathrm{CO}^{0,+}$ are (1) a simple association reaction (mechanism 1) and (2) a combination of association and dissociation (mechanism 2). These mechanisms are worked out below and are fitted to the experimental data.

\subsection{Mechanism 1: association reaction}

The most simple reaction mechanism, leading to the formation of $\mathrm{Au}_{n} \mathrm{~V}_{m} \mathrm{CO}^{0,+}$ complexes, comprises only one reaction step, namely a simple association reaction between $\mathrm{CO}$ and the clusters:

$$
\mathrm{Au}_{n} \mathrm{~V}_{m}^{0,+}+\mathrm{CO} \stackrel{k_{\mathrm{f}}^{(2)}}{\longrightarrow} \mathrm{Au}_{n} \mathrm{~V}_{m} \mathrm{CO}^{0,+}
$$

with $k_{\mathrm{f}}^{(2)}$ the bimolecular rate coefficient for the formation of the cluster-CO complex.

Since there is a continuous flow of $\mathrm{CO}$ gas in the reaction cell and only a negligible fraction of it is consumed, the concentration of $\mathrm{CO}$ gas is considered constant and the reaction can be described by pseudo-first order kinetics:

$$
\frac{\mathrm{d}\left[\mathrm{Au}_{n} \mathrm{~V}_{m}^{0,+}\right]}{\mathrm{d} t}=-k_{\mathrm{f}}^{(2)}[\mathrm{CO}]\left[\mathrm{Au}_{n} \mathrm{~V}_{m}^{0,+}\right]=-k_{\mathrm{f}}^{(1)}\left[\mathrm{Au}_{n} \mathrm{~V}_{m}^{0,+}\right]
$$

with $k_{\mathrm{f}}^{(1)}=k_{\mathrm{f}}^{(2)}[\mathrm{CO}]$ the pseudo-first order rate coefficient.

Integrating eqn (2) results in:

$$
\frac{\left[\mathrm{Au}_{n} \mathrm{~V}_{m}^{0,+}\right]}{\left[\mathrm{Au}_{n} \mathrm{~V}_{m}^{0,+}\right]_{0}}=\exp \left(-k_{\mathrm{f}}^{(1)} t\right)=\exp \left[-k_{\mathrm{f}}^{(2)} t \frac{p_{\mathrm{CO}}}{k_{\mathrm{B}} T_{\mathrm{CO}}}\right]
$$

$\left[\mathrm{Au}_{n} \mathrm{~V}_{m}{ }^{0,+}\right]_{0}$ and $\left[\mathrm{Au}_{n} \mathrm{~V}_{m}{ }^{0,+}\right]$ represent the intensities of the $\mathrm{Au}_{n} \mathrm{~V}_{m}{ }^{0,+}$ cluster before and after reacting with the $\mathrm{CO}$ gas, respectively, $t$ is the reaction time (i.e., the time the cluster spends in the reaction cell), $k_{\mathrm{B}}$ the Boltzmann constant, $p_{\mathrm{CO}}$ the pressure of the $\mathrm{CO}$ gas in the cell, and $T_{\mathrm{CO}}$ the temperature of the $\mathrm{CO}$ gas, which is set equal to room temperature. The reaction time $t$ is the passage time of the cluster through the reaction cell and is fixed by the dimensions of the experimental setup. Instead, $p_{\mathrm{CO}}$ can be changed and the kinetic data consist of relative intensities of the cluster and the cluster-CO complex as a function of the $\mathrm{CO}$ pressure. Fitting eqn (3) to the kinetic data allows for the determination of $k_{\mathrm{f}}^{(2)}$.

\subsection{Mechanism 2: association and dissociation reaction}

Given that there is no thermalization of the reaction products in the low-pressure collision cell, dissociation of the reaction products should be considered. Because the association reaction only takes place inside the cell, while dissociation can happen both inside and after leaving the reaction cell, a two-stage mechanism is proposed. Inside the reaction cell both association and dissociation are accounted for, while after leaving the cell and before extraction into the RTOF, only dissociation is possible. This leads to the following reaction mechanism:

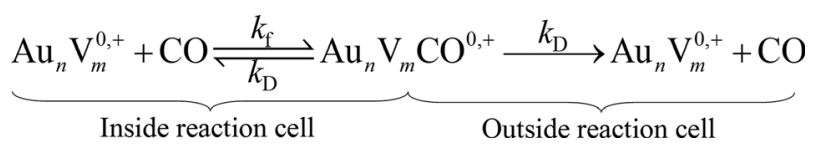

$k_{\mathrm{f}}$ is the bimolecular rate coefficient for the formation of the cluster-CO complex and $k_{\mathrm{D}}$ is the unimolecular dissociation rate coefficient. The integrated rate equation for this mechanism is given by:

$$
\begin{aligned}
\frac{\left[\mathrm{Au}_{n} \mathrm{~V}_{m}^{0,+}\right]}{\left[\mathrm{Au}_{n} \mathrm{~V}_{m}^{0,+}\right]_{0}}= & 1-\frac{k_{\mathrm{f}} p_{\mathrm{CO}}}{k_{\mathrm{f}} p_{\mathrm{CO}}+k_{\mathrm{D}} k_{\mathrm{B}} T_{\mathrm{CO}}} \exp \left(-k_{\mathrm{D}} t_{\mathrm{bc}}\right) \\
& \times\left\{1-\exp \left[-\left(k_{\mathrm{f}} \frac{p_{\mathrm{CO}}}{k_{\mathrm{B}} T_{\mathrm{CO}}}+k_{\mathrm{D}}\right) t_{\mathrm{ab}}\right]\right\}
\end{aligned}
$$

$t_{\mathrm{ab}}$ and $t_{\mathrm{bc}}$ denote the time the cluster spends inside the reaction cell and between the cell and the ion extraction, respectively.

The forward rate coefficient $k_{\mathrm{f}}$ can be approximated using collision theory: ${ }^{53}$

$$
k_{\mathrm{f}}=\sigma v \exp \left(-\frac{E_{\mathrm{a}}}{k_{\mathrm{B}} T}\right) P
$$

The steric factor $P$ takes into account the effect of the collision orientation while the energy factor $\exp \left(-\frac{E_{\mathrm{a}}}{k_{\mathrm{B}} T}\right)$ represents the presence of an energetic barrier equal to the activation energy $\left(E_{\mathrm{a}}\right) . \sigma$ is the collisional cross-section and $v$ the relative velocity of the cluster and the $\mathrm{CO}$ molecule. A few assumptions are made in order to determine $k_{\mathrm{f}}$. First of all, the hard-sphere model is used for the cross-section:

$$
\sigma=\pi\left(R_{n}+R_{\mathrm{CO}}\right)^{2}
$$

The hard-sphere radius of the cluster, $R_{n}=r_{\mathrm{b}} n^{1 / 3}+d$, is approximated assuming bulk density $\left(r_{\mathrm{b}}\right.$ is the radius of an atom with bulk metal density) and a spherical cluster shape 
where a constant value $d$ is included to account for surface roughness and interaction outside the hard-sphere cross section. The hard-sphere radius of $\mathrm{Au}_{n} \mathrm{~V}_{m}{ }^{0,+}(m=1-3)$ is assumed to be equal to the radius of $A u_{n+m}$. A typical value of $0.5 \AA$ is used for the correction term $d$ and $R_{\mathrm{CO}}$ is set to $1.9 \AA$. The hard sphere collision rate is an upper limit for the real forward rate coefficient. It should, however, be noted that the hard sphere collision rate for cationic clusters may be slightly higher since it was shown that a charge center can increase the hard sphere cross section in reactions between metal clusters and polarizable molecules. ${ }^{54}$ Given the temperature range and the size range considered in the present work, the Langevin rate $\left(6.5 \times 10^{-10} \mathrm{~cm}^{3} \mathrm{~s}^{-1}\right)$ is smaller than the hard-sphere collision rate $\left(8 \times 10^{-10}-1.8 \times 10^{-9} \mathrm{~cm}^{3} \mathrm{~s}^{-1}\right)$. Therefore, the hard-sphere collision rate is used opposed to the Langevin rate that is considered by several other authors for the cationic clusters. ${ }^{39,46,49}$ Fitting the model to the data, nonetheless, demonstrated that the calculated hard sphere collision rate is a realistic approximation for $k_{\mathrm{f}}$.

The relative velocity $v$ between the cluster and the $\mathrm{CO}$ gas is calculated based on the experimentally determined absolute cluster velocity and a Maxwell-Boltzmann distribution for the $\mathrm{CO}$ velocity at room temperature. Depending on the cluster's temperature, its absolute velocity is $600-900 \mathrm{~m} \mathrm{~s}^{-1}$ and the relative velocity is, also depending on the temperature, about $10 \%-30 \%$ higher. $t_{\mathrm{ab}}$ and $t_{\mathrm{bc}}$ are calculated from the absolute velocity and the geometric configuration.

Applying a small steric factor $(P<0.8)$ and/or a relative high activation energy results in an inferior quality of the fitting. Because of this, we assume that (i) each collision leads to a reaction, meaning that there is no activation energy, or the energy factor is 1 , and (ii) the steric factor is 1 .

Under the above listed assumptions, the backward rate coefficient $k_{\mathrm{D}}$ is the only unknown quantity in eqn (5) and can be used as a fitting parameter when plotting the relative intensities of the cluster and the cluster-CO complex as a function of the $\mathrm{CO}$ pressure.

Fig. 3 shows as an example the kinetic data (open symbols) of the reaction between $\mathrm{CO}$ and $\mathrm{Au}_{16}$ (panel a) and $\mathrm{Au}_{11} \mathrm{~V}$ (panel b). The lines represent fits to these data obtained by applying mechanism 1 (red dotted lines) and mechanism 2 (blue solid lines), respectively. As can be seen in Fig. 3, mechanism 2 fits the data much better than mechanism 1 . For instance, fitting the data of $\mathrm{Au}_{11} \mathrm{~V}$ with mechanism 1 yields an $R^{2}$ value of 0.39 while the $R^{2}$ value of mechanism 2 amounts to 0.93 . Additionally, mechanism 2 without backward reaction outside the reaction cell (i.e., using eqn (5) with $t_{\mathrm{bc}}=0$ ) was considered. However, this mechanism clearly leads to a worse fit $\left(R^{2}=0.54\right.$ in the case of $\left.\mathrm{Au}_{11} \mathrm{~V}\right)$ as shown by the green dashed lines in Fig. 3 .

\subsection{Reaction considerations}

Since mechanism 2 yields a much better fit quality than mechanism 1 and more complex reaction mechanisms did not further improve the fit quality, mechanism 2 will be used in the following to describe the reactions of gold and vanadium doped gold clusters with $\mathrm{CO}$. Furthermore, the formation of cluster- $(\mathrm{CO})_{p}$, complexes with $p>1$ could also be excluded

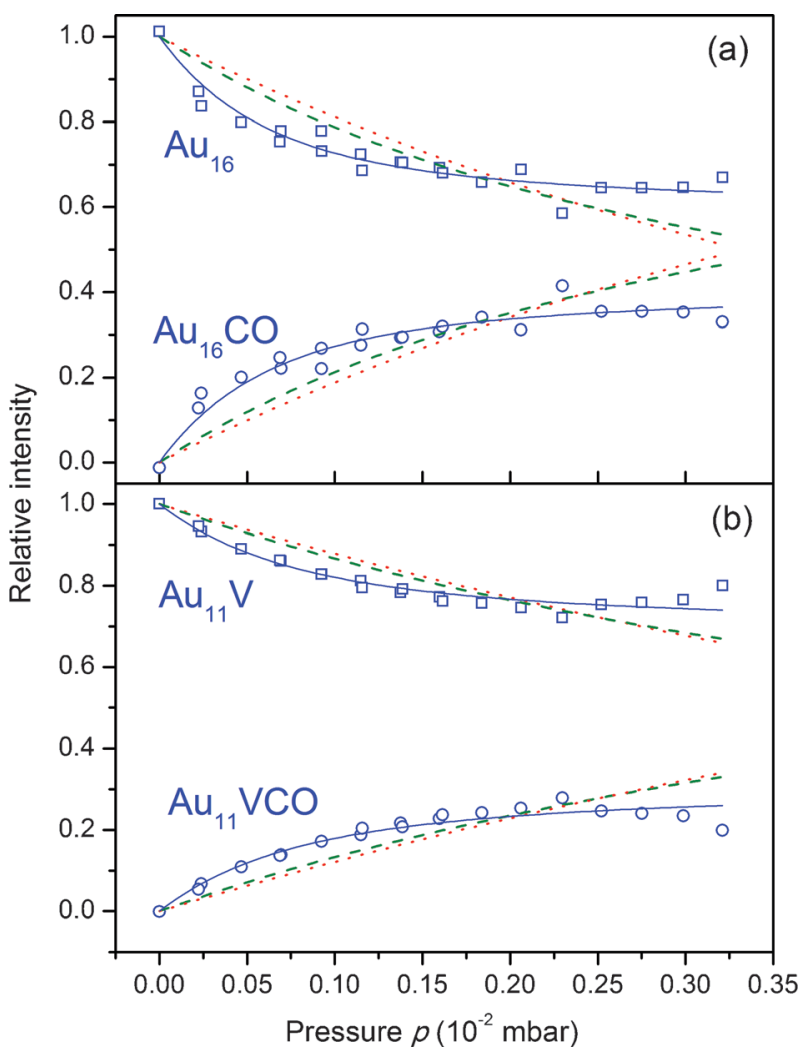

Fig. 3 Kinetic data (open symbols) of the reaction of neutral $\mathrm{Au}_{16}$ (a) and $\mathrm{Au}_{11} \mathrm{~V}$ (b) clusters with $\mathrm{CO}$. The clusters are produced at a source temperature of $168 \mathrm{~K}$. The red dotted and blue solid lines represent the fits according to eqn (3) and (5), respectively. The green dashed line corresponds to the fit using eqn (5) with $t_{\mathrm{bc}}=0$ (i.e., no dissociation outside the cell).

since in the current experiment, the corresponding $\mathrm{Au}_{n} \mathrm{~V}_{m}$ $(\mathrm{CO})_{p}{ }^{0,+}$ complexes were not observed.

The ratio $k_{\mathrm{f}} / k_{\mathrm{D}}$ will be used in the remainder to characterize the overall rate of the reaction. The higher the $k_{\mathrm{f}} / k_{\mathrm{D}}$ the more likely the formation of cluster-CO complexes. Please note that $k_{\mathrm{f}} / k_{\mathrm{D}}$ cannot be interpreted as the equilibrium constant, because no equilibrium between forward and backward reactions is obtained.

Mechanism 2 does not include a stabilization reaction since there is no inert gas present in the reaction cell to thermalize the reaction products. Given the low pressure in the reaction cell and the short interaction time, collisional cooling by other $\mathrm{CO}$ molecules is expected not to be effective. We tested a model including stabilization by collisions with $\mathrm{CO}$ which, however, resulted in a worse fit quality. Furthermore, also radiative cooling is expected to be too slow to be of relevance. Therefore, the formed reaction products are thermally excited (energized) and have a limited lifetime, which is directly reflected in the presence of the backward reaction. As an independent approach to verify the importance of the backward reaction, a RRKM analysis was performed to derive the lifetime of the energized complexes in the absence of a stabilization reaction. If the lifetime of the $\left(\mathrm{Au}_{n} \mathrm{CO}\right)^{*}$ complex is considerably larger than the time scale of the experiment (i.e., complexes need to travel on average from the middle of the reaction cell to the ion extraction, which takes approximately 
$100 \mu \mathrm{s})$, the dissociation reaction step can be neglected. If, however, the lifetime of $\left(\mathrm{Au}_{n} \mathrm{CO}\right)^{*}$ is smaller than the time scale of the experiment, reaction mechanism 2 has to be used.

Fig. 4 displays the RRKM lifetimes of $\mathrm{Au}_{n} \mathrm{CO}^{*}$ with $n=2-28$ for (a) different $\mathrm{CO}$ binding energies $E_{0}$ at $T=300 \mathrm{~K}$, (b) different binding energies $E_{0}$ at $T=124 \mathrm{~K}$, and (c) different cluster source temperatures $T$ at $E_{0}=0.80 \mathrm{eV}$. The chosen range of the binding energy $E_{0}=0.4-1.2 \mathrm{eV}$ is based on the $\mathrm{CO}$ binding energies for different cluster sizes available from the literature. ${ }^{28,41}$ The dotted line indicates the time the complexes need to travel from the middle of the reaction cell to the ion extraction. For the RRKM model a 'loose' transition state including a rotational barrier of $0.1 \mathrm{eV}$ was assumed. ${ }^{46,55,56}$ The vibrational frequencies of $\mathrm{Au}_{n} \mathrm{CO}^{*}$ were estimated using an elastic model for the frequencies of the $\mathrm{Au}_{n}$ metal clusters ${ }^{57}$ as well as $430 \mathrm{~cm}^{-1}$ and $2140 \mathrm{~cm}^{-1}$ for the $\mathrm{Au}_{n}-\mathrm{CO}$ and $\mathrm{Au}_{n} \mathrm{C}-\mathrm{O}$ stretching frequencies, respectively. Remaining low-frequency bending modes are set equal to $50 \mathrm{~cm}^{-1}$. Furthermore, it was assumed that the velocity of $\mathrm{CO}$ is negligible and there is no additional energy transfer due to the collision.

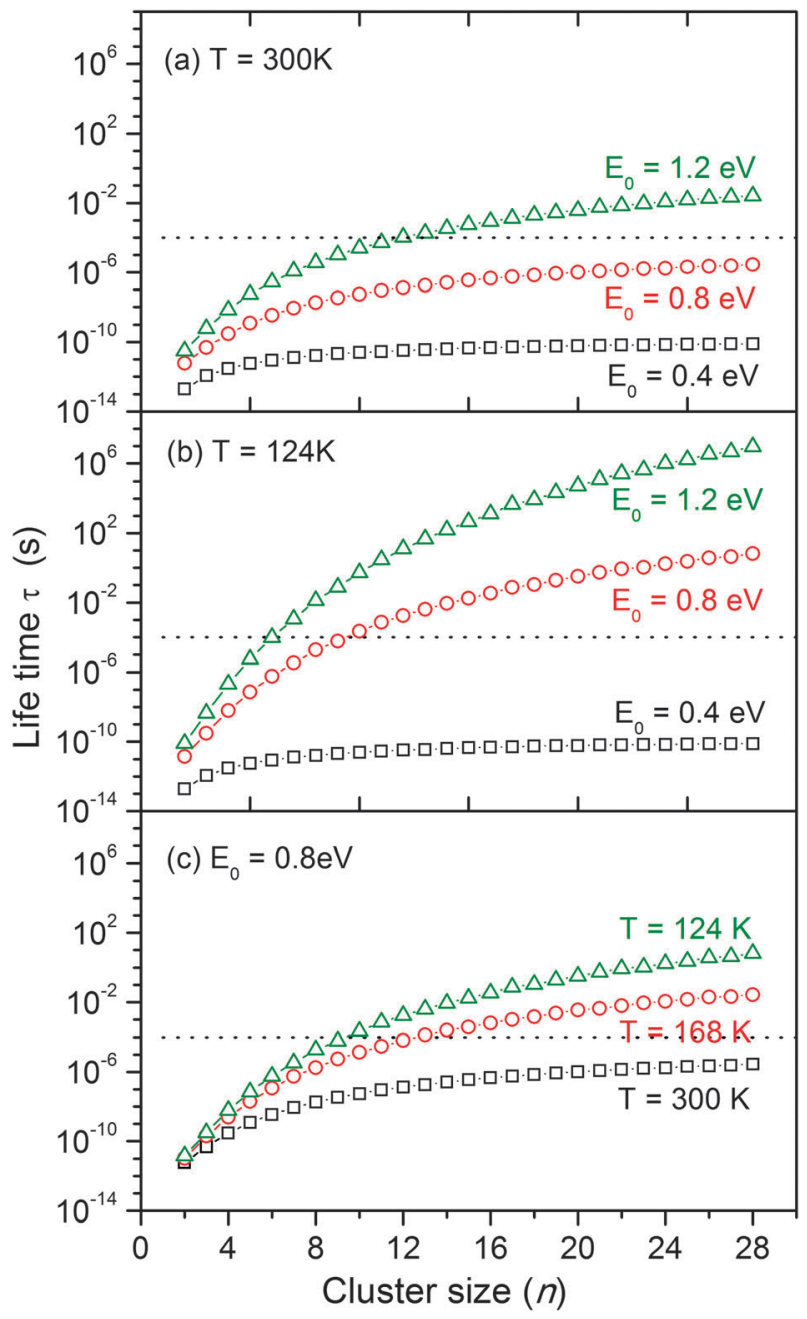

Fig. 4 Calculated lifetime of the energized $\mathrm{Au}_{n} \mathrm{CO} *$ complexes with $n=2-28$ obtained by employing RRKM theory for (a) $T=300 \mathrm{~K}$ and $E_{0}=0.20-1.0 \mathrm{eV}$; (b) $T=124 \mathrm{~K}$ and $E_{0}=0.20-1.0 \mathrm{eV}$; and (c) $E_{0}=0.80 \mathrm{eV}$ and $T=124-300 \mathrm{~K}$. The dotted line denotes the time scale of the experiment.
Fig. 4 demonstrates for all considered temperatures and binding energies that the lifetime increases with increasing cluster size. This can be understood by the fact that the number of degrees of freedom among which the energy can be distributed increases with increasing cluster size. Please note that in reality the increase of the lifetime with cluster size is not expected to be smooth because the $\mathrm{CO}$ binding energies are size dependent. From Fig. 4(a) it is apparent that at $T=300 \mathrm{~K}$ the lifetime of most of the complexes in the binding energy range of $E_{0}=0.4-1.2 \mathrm{eV}$ is considerably smaller than the time of the experiment, which means that the complexes $\mathrm{Au}_{n} \mathrm{CO}^{*}$ will easily decompose before detection. Consequently, the experimentally obtained kinetic data must be interpreted as a combination of complex formation and survival probability. However, at lower temperatures (see Fig. 4(b) for $T=124 \mathrm{~K}$ ), the lifetime of the energized complex $\mathrm{Au}_{n} \mathrm{CO}^{*}$ for $n>9$ becomes larger than the time scale of the experiment for $E_{0}>0.8 \mathrm{eV}$. This implies that if the binding energies are large enough, the backward reaction for larger sizes becomes less relevant at lower temperatures, which is reflected in reduced size dependences of the kinetic data. The enhancement of the backward rate with higher cluster temperature is demonstrated more clearly in Fig. 4(c) for a fixed $\mathrm{CO}$ binding energy of $E_{0}=0.80 \mathrm{eV}$.

\section{Results and discussion}

\subsection{Bare cationic gold clusters}

Before discussing the reactivity of the vanadium doped gold clusters, the reactivity of the bare cationic gold measured in the low pressure collision cell regime is compared with experiments performed using an ion trap.

Fig. 5 compares the reactivity of cationic $\mathrm{Au}_{n}{ }^{+}$clusters towards $\mathrm{CO}$ at room temperature obtained using these two techniques. The $k_{\mathrm{f}} / k_{\mathrm{D}}$ ratio obtained with the low-pressure collision cell (LPCC) technique are compared with the apparent rate coefficients $k_{\text {app }}$ observed for the $\mathrm{CO}$ adsorption on gold cluster cations $\mathrm{Au}_{n}{ }^{+}(n=5-35)$ using a Fourier transform ion cyclotron resonance mass spectrometer (FT-ICR) obtained by the Kappes group. ${ }^{49,65}$ They derived values for $k_{\text {app }}$ for multiple $\mathrm{CO}$ adsorption by measuring reaction kinetics upon varying the residence time in the ion trap. This $k_{\text {app }}$ with units $\mathrm{cm}^{3} \mathrm{~s}^{-1}$ is an overall reaction rate, which is a combination of a forward association rate, a backward dissociation rate, and a stabilizing radiative cooling rate. The radiative cooling in the ion trap cannot be ignored because of the long time scale of the ion trap experiment (several seconds compared to $100 \mu \mathrm{s}$ in the LPCC experiment). While in both techniques the derived quantities are a measure for the reactivity of the clusters, in the first case the rate coefficients are derived by varying the pressure and in the second case by varying the reaction time. Furthermore, in the ion trap the reaction is able to reach an equilibrium state, while using the LPCC technique this is not the case. This is also apparent by the absence of multiple $\mathrm{CO}$ absorption using the LPCC technique as opposed to the results from the ion trap. Remark also the general increase in $k_{\mathrm{f}} / k_{\mathrm{D}}$ with cluster size using the LPCC technique, which is related to the difficulty to accommodate the heat of formation in the small clusters 


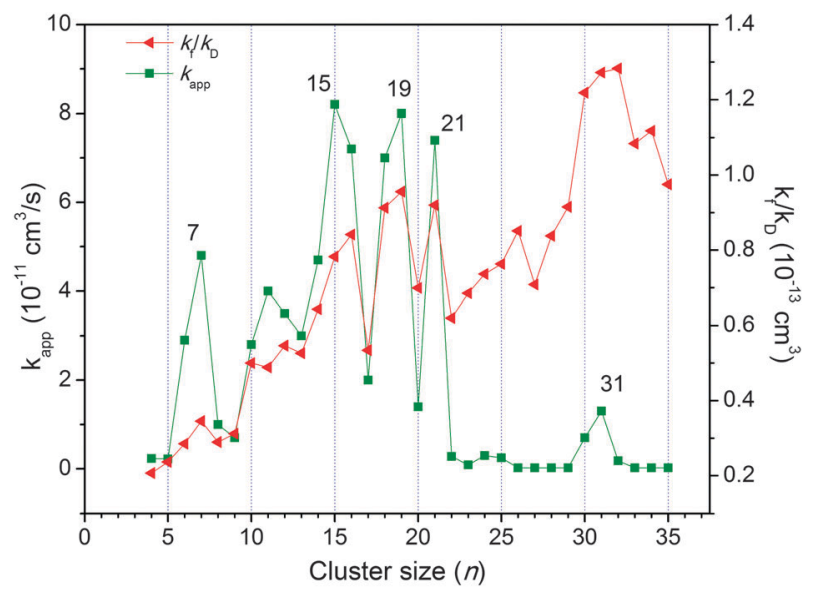

Fig. 5 Reactivity of cationic $\mathrm{Au}_{n}{ }^{+}$clusters toward $\mathrm{CO}$ at room temperature obtained with two different techniques: a low-pressure collision reaction cell technique $(<)$ and an ion cyclotron resonance trap technique ( $\square$ ). Data obtained with the ion cyclotron resonance trap technique are taken from ref. 49 and 65 .

(see Section 3.3). This trend is not observed for the reactions in the ion trap, which implies that the reaction products in the FT-ICR must be stabilized.

Despite these very different overall reaction conditions and reaction times, the cluster size dependent reactivity (local maxima in $k_{\mathrm{f}} / k_{\mathrm{D}}$ at $n=7,15-16,18-19,21,26$, and 30-32) is in excellent agreement (except for the maximum at $n=26$ ). The similarity between our measured rate coefficient ratio and the reaction rate coefficient in the FT-ICR experiments supports the applicability of the low-pressure reaction cell technique to study the reactivity of clusters. The LPCC technique has one important advantage over ion traps, namely that it allows for the experimental investigation of both neutral and charged species.

\subsection{Neutral vanadium doped gold clusters}

Fig. 6 shows the rate coefficient ratio $k_{\mathrm{f}} / k_{\mathrm{D}}$ as a function of the number of gold atoms for neutral $\mathrm{Au}_{n} \mathrm{~V}_{m}(n=8-30 ; m=0-3)$ clusters produced at two different source temperatures of $124 \mathrm{~K}$ (red squares) and $168 \mathrm{~K}$ (green circles). The error bars on the ratio $k_{\mathrm{f}} / k_{\mathrm{D}}$ represent the standard deviation on the fitting parameters when the kinetic model is fitted to the experimental data and reflect the size-to-size uncertainties. There is also an uncertainty on the absolute $k_{\mathrm{f}} / k_{\mathrm{D}}$ values, originating from the pressure measurements, the baseline determination, the velocity measurements, and the assumptions of the $k_{\mathrm{f}}$ determination. The systematic errors, which are estimated to be about $50 \%$, are not expected to change the obtained size dependence and are not included in the error bars. The larger the $k_{\mathrm{f}} / k_{\mathrm{D}}$, the more likely the cluster-CO complexes are observed in the experiment. Both bare and doped clusters show a clear increase of $k_{\mathrm{f}} / k_{\mathrm{D}}$ with decreasing cluster temperature due to a decrease in the unimolecular decomposition rate coefficient $k_{\mathrm{D}}$. This is according to expectations since the lifetime of the cluster-CO complex increases with decreasing temperature as discussed in Section 3.3.

Fig. 6a shows the rate coefficient ratio for the bare $\mathrm{Au}_{n}$ clusters (with $n \leq 22$ ). A clear odd-even staggering dominates

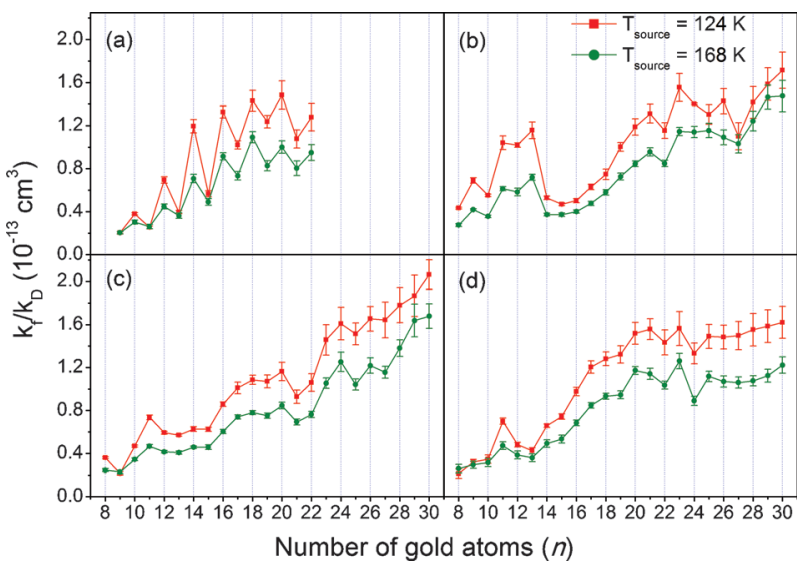

Fig. 6 The ratio $k_{\mathrm{f}} / k_{\mathrm{D}}$ as a function of number of gold atoms $n$ in the neutral clusters (a) $\mathrm{Au}_{n}$, (b) $\mathrm{Au}_{n} \mathrm{~V}$, (c) $\mathrm{Au}_{n} \mathrm{~V}_{2}$, and (d) $\mathrm{Au}_{n} \mathrm{~V}_{3}$ obtained at $168 \mathrm{~K}(\bullet)$ and $124 \mathrm{~K}(\square)$.

the rate coefficient ratio pattern of neutral $\mathrm{Au}_{n}$ clusters with the even numbers of the $\mathrm{Au}$ atoms having the highest reactivity. This odd-even staggering, which is likely related to electron pairing of the gold $6 \mathrm{~s}^{1}$ valence electrons, indicates that the electronic shell structure is important for the $\mathrm{CO}$ reactivity. Furthermore, $k_{\mathrm{f}} / k_{\mathrm{D}}$ distinctly drops after $n=14$ and 20, as already discussed in our earlier work. ${ }^{15,16}$ A correlation between the $\mathrm{CO}$ reactivity and the electronic shell structure was found, exhibiting enhanced reactivity for cluster sizes with a closed electronic shell or subshell. ${ }^{15,16}$ Specifically, the $\mathrm{Au}_{20}$ cluster has 20 delocalized electrons, corresponding to completion of $1 \mathrm{~S}^{2} / 1 \mathrm{P}^{6} / 1 \mathrm{D}^{10} / 2 \mathrm{~S}^{2}$ shells, ${ }^{21,22,58}$ if one assumes that the atomic $6 s^{1}$ electrons of each gold atom are delocalized over the cluster volume. The maximum at the $\mathrm{Au}_{14}$ cluster may be attributed to an electronic subshell closure. $\mathrm{Au}_{14}$ is Jahn-Teller distorted and has an oblate geometry.

The rate coefficient ratios for the vanadium doped $\mathrm{Au}_{n} \mathrm{~V}$, $\mathrm{Au}_{n} \mathrm{~V}_{2}$, and $\mathrm{Au}_{n} \mathrm{~V}_{3}$ clusters (see Fig. 6b, c, and d) demonstrate that the size dependent reactivity toward $\mathrm{CO}$ adsorption changes strongly upon vanadium doping. There is still a gradual increase with increasing cluster size, in agreement with the limited possibility to accommodate the heat of formation in small clusters, as discussed in Section 3.3. However, the odd-even staggering of the $\mathrm{CO}$ reactivity, which is strongly present for bare $\mathrm{Au}_{n}$, becomes much less pronounced with increasing amount of vanadium doping. For $\mathrm{Au}_{n} \mathrm{~V}$, there is odd-even staggering for $n \leq 14$, but it disappears completely for $\mathrm{Au}_{n} \mathrm{~V}_{2}$ and $\mathrm{Au}_{n} \mathrm{~V}_{3}$. The rate coefficient ratio in the case of $\mathrm{Au}_{n} \mathrm{~V}$ shows a remarkably steep drop after $n=13$, followed by a gradual increase with size up to $n=21$. There are also drops in $k_{\mathrm{f}} / k_{\mathrm{D}}$ after $n=21$ and 26. The special feature in the reactivity of $\mathrm{Au}_{n} \mathrm{~V}$ at $n=13$ can be related to either electronic shell closure or geometric effects. The location of $\mathrm{V}$ in the clusters is important since $\mathrm{CO}$ might preferentially bind to the $\mathrm{V}$ atom. However, a recent theoretical study, ${ }^{59}$ in which trends in structural, electronic, and energetic properties of bimetallic $\mathrm{Au}_{n} \mathrm{~V}(n=1-14)$ clusters were studied, has shown that the transition from exohedral to endohedral is gradual and the encapsulation of vanadium is complete at $n=11$. Therefore, the drop in $\mathrm{CO}$ reactivity after $\mathrm{Au}_{13} \mathrm{~V}$ is likely related to an 
electronic shell closure and not to the onset of geometric encapsulation of the dopant atom. This size corresponds to a closed shell system with 18 valence electrons, if five electrons (i.e., the atomic $3 \mathrm{~d}^{3} 4 \mathrm{~s}^{2}$ electrons) are counted for vanadium. This is in agreement with the DOS of $\mathrm{Au}_{13} \mathrm{~V}$ which shows a sixfold pseudo degenerate HOMO right after the gold d-band. ${ }^{60}$ The LUMO is a distinct four-fold pseudo degenerate orbital. The gradual increase in reactivity from $\mathrm{Au}_{14} \mathrm{~V}$ to $\mathrm{Au}_{21} \mathrm{~V}$ can be related to the filling of electrons in this new subshell. The disappearance of the 20 electron shell closing, in contrast with the $\mathrm{CO}$ reactivity of bare $\mathrm{Au}_{20}$, can be explained by the presence of a central less electronegative dopant. ${ }^{22}$

Both $\mathrm{Au}_{n} \mathrm{~V}_{2}$ and $\mathrm{Au}_{n} \mathrm{~V}_{3}$ show a distinct maximum at $n=11$. While the simple electron-counting rules can be used for singly vanadium doped clusters, they do not seem to be readily applicable for multiple doped $\mathrm{Au}_{n} \mathrm{~V}_{m>1}$ clusters. As a transition metal, it is typical for vanadium to have multiple oxidation states, or in other words, vanadium can have different numbers of delocalized electrons depending on the interaction between the vanadium atom with the other atoms in the system. Hence, more detailed information on how the second and third vanadium bind to each other and/or to the cluster is essential for the interpretation of the size dependent reactivity of $\mathrm{Au}_{n} \mathrm{~V}_{m>1}$.

\subsection{Cationic vanadium doped gold clusters}

Fig. 7 shows the rate coefficient ratio $k_{\mathrm{f}} / k_{\mathrm{D}}$ for cationic $\mathrm{Au}_{n} \mathrm{~V}_{m}{ }^{+}(n=5-30 ; m=0-3)$ clusters produced at two different source temperatures of $124 \mathrm{~K}$ and $168 \mathrm{~K}$.

Comparing the absolute $k_{\mathrm{f}} / k_{\mathrm{D}}$ values of cationic and neutral (both bare and vanadium doped) clusters $\mathrm{Au}_{n} \mathrm{~V}_{0-3}{ }^{0,+}$ ( $c f$. Fig. 6 and 7) reveals a considerably enhanced reactivity of the cationic clusters. Two contributions are responsible for this reaction behavior. The first contribution arises from the interaction of the $\mathrm{CO}$ dipole moment with the electrostatic field associated to the charge distribution of the clusters. For cationic clusters, this electrostatic field-CO dipole interaction is much stronger compared to that of the neutral clusters. ${ }^{61}$ The second contribution originates in details of the $\mathrm{CO}$ bonding as described by the Blyholder model. ${ }^{62}$ According to this model the on top bonding of the $\mathrm{CO}$ molecule to the metal particle consists of a $\sigma$ forward-donation from the $5 \sigma$ lone pair of $\mathrm{CO}$ into an orbital with the appropriate symmetry and a $\pi$ back-donation from a $\mathrm{d} \pi$ orbital into the empty antibonding $2 \pi^{*}$ orbital of $\mathrm{CO}$. The $\sigma$ donation is generally expected to be efficient for electron acceptors, ${ }^{19}$ which explains the higher reactivity observed for the cation than for the neutral clusters. This is in agreement with the work done by $\mathrm{Wu}$ and co-workers, ${ }^{63}$ in which the $\mathrm{CO}$ adsorption onto small cationic, neutral and anionic gold clusters was studied. Their calculation also showed that the $\mathrm{C}-\mathrm{O}$ in the $\mathrm{Au}_{n} \mathrm{CO}^{+}$complex has a higher vibrational frequency than that in the neutral $\mathrm{Au}_{n} \mathrm{CO}$, indicating a weaker $\mathrm{C}-\mathrm{O}$ bond in $\mathrm{Au}_{n} \mathrm{CO}^{+}$, or in other words, a stronger interaction of the cationic clusters than the neutral ones with the CO molecule.

For the larger sizes $(n>15)$ one can also note that $k_{\mathrm{f}} / k_{\mathrm{D}}$ shows a decrease with increasing cluster size for the cations, opposed to a general increase for the neutrals. The absolute

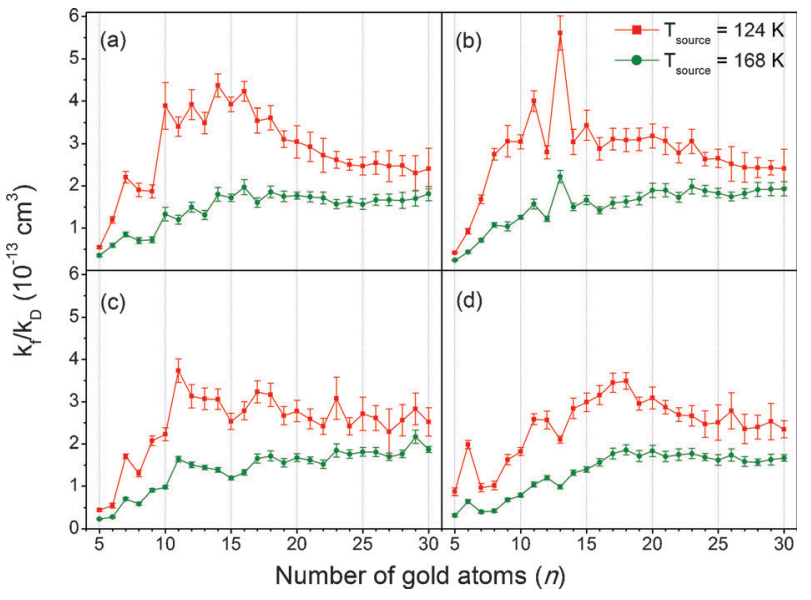

Fig. 7 The ratio $k_{\mathrm{f}} / k_{\mathrm{D}}$ as a function of the number of gold atoms $n$ in the cationic clusters (a) $\mathrm{Au}_{n}{ }^{+}$, (b) $\mathrm{Au}_{n} \mathrm{~V}^{+}$, (c) $\mathrm{Au}_{n} \mathrm{~V}_{2}{ }^{+}$, and (d) $\mathrm{Au}_{n} \mathrm{~V}_{3}{ }^{+}$obtained at $168 \mathrm{~K}(\bullet)$ and $124 \mathrm{~K}(\square)$.

values of $k_{\mathrm{f}} / k_{\mathrm{D}}$ for the neutral and cationic $\mathrm{Au}_{n} \mathrm{~V}_{m}{ }^{0,+}$ become comparable for the largest sizes studied in the current work $(n>25)$. This can be understood by simple electrostatic considerations. The charge of the cluster is distributed within a larger volume so the excess charge density is getting smaller. In addition, the center of charge of the cluster is likely to be further away from the adsorbed $\mathrm{CO}$ molecule. This results in the saturation of the cluster's reactivity at larger sizes $(n>25)$.

For bare $\mathrm{Au}_{n}{ }^{+}$clusters at $124 \mathrm{~K}$ and $168 \mathrm{~K}$ (see Fig. 7a), the odd-even staggering is less pronounced than that of the neutrals and limited to the size range $n=9-18$. Remarkably, the odd-even staggering in this region shows the same maxima, when expressed as number of atoms, as in the neutral clusters. This implies that for the cationic clusters not the even-electron clusters but the odd-electron clusters are the most reactive. Also this phenomenon can be explained on the basis of the Blyholder model for the cluster- $\mathrm{CO}$ bond. While the strength of the $\sigma$ donation decreases going from cation to neutral, the $\pi$ back donation, on the other hand, is the largest for the anion and decreases with the order anion $>$ neutral $>$ cation. This is due to the less negative charge available for back donation in the cluster going from anion over neutral to cation. Since the CO $2 \pi^{*}$ orbital is antibonding, the strong $\pi$ back donation in the case of the anion weakens the $\mathrm{C}-\mathrm{O}$ bond and results in a red-shift of its vibrational frequency which was observed experimentally ${ }^{64}$ and theoretically. ${ }^{61,63}$ For the cation the $\sigma$ donation will outweigh the $\pi$ back donation and there is a net charge transfer from the $\mathrm{CO}$ molecule to the cluster to form an ionic-like bond: $\mathrm{Au}^{-\delta}-\mathrm{CO}^{+\delta}$. In terms of simple electron counting rules the $\mathrm{CO}$ "donates" "one" electron (the actual charge transfer is less than an entire electron) to the cluster and a shell closing of $n$ electrons will appear in the reactivity pattern for a cationic cluster with $n-1$ delocalized electrons. For the neutral cluster the $\sigma$ donation and the $\pi$ donation have about the same charge transfer. ${ }^{61}$

For bare $\mathrm{Au}_{n}{ }^{+}$clusters at room temperature (see Fig. 5) the odd-even staggering is no longer present and some strong features appear for species with an odd number of atoms. The maxima at sizes 15,19 , and 21 compare well with the shell closings at 14,18 , and 20 , known for gold clusters. 
Due to the lack of further experimental results at room temperature, we will omit the discussion on these features here.

The rate coefficient ratios of the doped $\mathrm{Au}_{n} \mathrm{~V}^{+}, \mathrm{Au}_{n} \mathrm{~V}_{2}{ }^{+}$, and $\mathrm{Au}_{n} \mathrm{~V}_{3}{ }^{+}$clusters are plotted in Fig. $7 \mathrm{~b}-\mathrm{d}$, respectively. The strong size dependence in their rate coefficient ratio is limited to the size range $n=4-18$. From $n=18$ onwards, the reactivity does not vary much among different sizes.

Similar as for the bare gold clusters, the most reactive $\mathrm{Au}_{n} \mathrm{~V}^{+}$clusters have the same size as the most reactive $\mathrm{Au}_{n} \mathrm{~V}$ clusters. For the singly doped vanadium, the sharp drop after size $n=13$ is preserved, as well as the drops after sizes $n=11$ and 21. For $\mathrm{Au}_{n} \mathrm{~V}_{2}{ }^{+}$maxima are found at $n=7,11,17-18$, and 23 . Reactivity of the $\mathrm{Au}_{n} \mathrm{~V}_{3}{ }^{+}$clusters drops at $n=7,13$, and 19 . These systems show maxima at odd numbers of gold atoms, the same as for the neutrals, once again showing no reversal in the odd-even staggering compared to the neutrals.

Cooling the clusters to $124 \mathrm{~K}$ results in an increased reactivity and a more pronounced size dependence of $k_{\mathrm{f}} / k_{\mathrm{D}}$ while the global features remain the same at $124 \mathrm{~K}$ and $168 \mathrm{~K}$.

\section{Conclusions}

In conclusion we demonstrated that gas phase reactivity measurements in a low-pressure collision cell can be used to study the reactions of both charged and neutral clusters with small molecules. Analysis of the kinetic data, measured as a function of the pressure in the reaction cell, demonstrated that the reaction mechanism is composed of an association and a dissociation reaction with the latter also proceeding once the clusters leave the cell.

Since no stabilization reaction takes places on the time scale of the experiment, the overall reaction rate is limited by the lifetime of the energized complex. Calculated lifetimes, employing RRKM theory, confirm this assumption. Reaction rates for bare $\mathrm{Au}_{n}{ }^{+}$with $\mathrm{CO}$ were compared with apparent reaction rates of the same system studied in an FT-ICR ion trap. ${ }^{49,65}$ Agreement of the size dependences of the reaction rates demonstrates that the low-pressure collision cell measurements are a valuable alternative to perform gas-phase reactivity studies of small clusters.

The technique was applied to study the reactivity of neutral and cationic vanadium doped gold clusters, $\mathrm{Au}_{n} \mathrm{~V}_{m}{ }^{0,+}$ with $n<30,0 \leq m \leq 3$. The main observations are: (i) the cationic clusters are considerably more reactive towards $\mathrm{CO}$ than the neutral clusters; (ii) the reactivity of singly doped neutral $\mathrm{Au}_{n} \mathrm{~V}$ is significantly different from bare $\mathrm{Au}_{n}$ with a pronounced drop in $k_{\mathrm{f}} / k_{\mathrm{D}}$ after $\mathrm{Au}_{13} \mathrm{~V}$, corresponding to an 18-electron shell closure; (iii) there is no reversal of the odd-even staggering in the number of atoms going from neutral to cationic clusters related to a different charge transfer upon $\mathrm{CO}$ attachment for neutral and cationic clusters (except for cationic gold clusters at room temperature); and (iv) the overall reactivity decreases with increasing temperature because the reaction is limited by the lifetime of the excited complexes.

\section{Acknowledgements}

This work is supported by the Fund for Scientific ResearchFlanders (FWO), the KU Leuven Research Council
(GOA and IDO programs), and the Belgian Interuniversity Attraction Poles (IAP) research program. H.T.L. thanks the Vietnamese Government (MOET program 322) and S.M.L. is grateful for support from the FWO.

\section{References}

1 M. Haruta, Nature, 2005, 437, 1098.

2 M. Haruta, Catal. Today, 1997, 36, 153.

3 W. T. Wallace and R. L. Whetten, J. Phys. Chem. B, 2000, 104, 10964.

4 J. Y. Lee and J. Schwank, J. Catal., 1986, 102, 207.

5 T. M. Salama, Y. Ohnishi and M. Ichikawa, J. Chem. Soc., Faraday Trans., 1996, 92, 301.

6 T. Hayashi, K. Tanaka and M. Haruta, J. Catal., 1998, 178, 566.

7 D. Andreeva, V. Idakiev, T. Tabakova and A. Andreev, J. Catal., 1996, 158, 354.

8 T. Tabakova, V. Idakiev, D. Andreeva and I. Mitov, Appl. Catal., A, 2000, 202, 9 .

9 T. V. Choudhary and D. W. Goodman, Top. Catal., 2002, 21, 25.

10 M. A. Nygren, P. E. M. Siegbahn, C. Jin, T. Guo and R. E. Smalley, J. Chem. Phys., 1991, 95, 6181.

11 T. H. Lee and K. M. Ervin, J. Phys. Chem., 1994, 98, 10023.

12 J. Hagen, L. D. Socaciu, U. Heiz, T. M. Bernhardt and L. Wöste, Eur. Phys. J. D, 2003, 24, 327.

13 D. M. Popolan, M. Nößler, R. Mitrić, T. M. Bernhardt and V. Bonačić-Koutecký, Phys. Chem. Chem. Phys., 2010, 12, 7865.

14 W. T. Wallace and R. L. Whetten, J. Am. Chem. Soc., 2002, 124, 7499.

15 N. Veldeman, P. Lievens and M. Andersson, J. Phys. Chem. A, 2005, 109, 11793.

16 J. De Haeck, N. Veldeman, P. Claes, E. Janssens, M. Andersson and P. Lievens, J. Phys. Chem. A, 2011, 115, 2103.

17 I. Balteanu, O. P. Balaj, B. S. Fox, M. K. Beyer, Z. Bastl and V. E. Bondybey, Phys. Chem. Chem. Phys., 2003, 5, 1213.

18 E. M. Fernández, P. Ordejón and L. C. Balbás, Chem. Phys. Lett., 2005, 408, 252.

19 A. Prestianni, A. Martorana, F. Labat, I. Ciofini and C. Adamo, J. Phys. Chem. B, 2006, 110, 12240.

20 A. Prestianni, A. Martorana, I. Ciofini, F. Labat and C. Adamo, J. Phys. Chem. C, 2008, 112, 18061.

21 S. Neukermans, E. Janssens, H. Tanaka, R. E. Silverans and P. Lievens, Phys. Rev. Lett., 2003, 90, 033401.

22 E. Janssens, S. Neukermans and P. Lievens, Curr. Opin. Solid State Mater. Sci., 2004, 8, 185.

23 M. B. Torres, E. M. Fernández and L. C. Balbás, Phys. Rev. B: Condens. Matter Mater. Phys., 2005, 71, 155412.

24 S. M. Lang, P. Claes, N. T. Cuong, M. T. Nguyen, P. Lievens and E. Janssens, J. Chem. Phys., 2011, 135, 224305.

25 H. Häkkinen, S. Abbet, A. Sanchez, U. Heiz and U. Landman, Angew. Chem., Int. Ed., 2003, 42, 1297.

26 F. Tielens, J. Andrés, M. Van Brussel, C. Buess-Hermann and P. Geerlings, J. Phys. Chem. B, 2005, 109, 7624.

27 K. Koszinowski, D. Schröder and H. Schwarz, ChemPhysChem, $2003,4,1233$.

28 L. Lin, P. Lievens and M. T. Nguyen, Chem. Phys. Lett., 2010, 498, 296.

29 A. M. Joshi, M. H. Tucker, W. N. Delgass and K. T. Thomson, J. Chem. Phys., 2006, 125, 194707.

30 C. Song, Q. Ge and L. Wang, J. Phys. Chem. B, 2005, 109, 22341.

31 M. P. Johansson and P. Pyykkö, Chem. Commun., 2010, 46, 3762.

32 Y. Fu, J. Li and S.-G. Wang, J. Mol. Model., 2009, 16, 9.

33 J. Graciani, J. Oviedo and J. F. Sanz, J. Phys. Chem. B, 2006, $110,11600$.

34 P. Weis, O. Welz, E. Vollmer and M. M. Kappes, J. Chem. Phys., 2004, 120, 677.

35 L. M. Wang, R. Pal, W. Huang, X. C. Zeng and L. S. Wang, J. Chem. Phys., 2010, 132, 114306.

36 S. Zhao, Y. L. Ren, J. J. Wang and W. P. Yin, J. Phys. Chem. A, 2010, 114, 4917.

37 T. M. Bernhardt, Int. J. Mass Spectrom., 2005, 243, 1.

38 T. M. Bernhardt, J. Hagen, S. M. Lang, D. M. Popolan, L. D. Socaciu-Siebert and L. Wöste, J. Phys. Chem. A, 2009, $113,2724$. 
39 T. M. Bernhardt, L. D. Socaciu-Siebert, J. Hagen and L. Wöste, Appl. Catal., A, 2005, 291, 170.

40 M. Neumaier, F. Weigend, O. Hampe and M. M. Kappes, J. Chem. Phys., 2006, 125, 104308.

41 M. Neumaier, F. Weigend, O. Hampe and M. M. Kappes, Faraday Discuss., 2008, 138, 393.

42 Y. Zhao, Z. Li and J. Yang, Phys. Chem. Chem. Phys., 2009, 11, 2329.

43 N. K. Jena, K. R. S. Chandrakumar and S. K. Ghosh, J. Phys. Chem. C, 2009, 113, 17885.

44 S. M. Lang, T. M. Bernhardt, R. N. Barnett and U. Landman, Angew. Chem., Int. Ed., 2010, 49, 980.

45 S. M. Lang, T. M. Bernhardt, R. N. Barnett and U. Landman, J. Phys. Chem. C, 2011, 115, 6788.

46 T. M. Bernhardt, J. Hagen, S. M. Lang, D. M. Popolan, L. D. Socaciu-Siebert and L. Wöste, J. Phys. Chem. A, 2009, 113, 2724.

47 J. Hagen, L. D. Socaciu-Siebert, J. Le Roux, D. M. Popolan, S. Vajda, T. M. Bernhardt and L. Wöste, Int. J. Mass Spectrom., 2007, 261, 152.

48 L. D. Socaciu, J. Hagen, J. Le Roux, D. Popolan, T. M. Bernhardt, L. Wöste and S. Vajda, J. Chem. Phys., 2004, 120, 2078.

49 M. Neumaier, F. Weigend, O. Hampe and M. M. Kappes, J. Chem. Phys., 2005, 122, 104702.

50 L. Holmgren, H. Grönbeck, M. Andersson and A. Rosén, Phys. Rev. B: Condens. Matter, 1996, 53, 16644.
51 W. Bouwen, P. Thoen, F. Vanhoutte, S. Bouckaert, F. Despa, H. Weidele, R. E. Silverans and P. Lievens, Rev. Sci. Instrum., $2000,71,54$.

52 M. Andersson, J. L. Persson and A. Rosén, J. Phys. Chem., 1996, 100, 12222.

53 S. K. Upadhyay, Chemical kinetics and reaction dynamics, Springer and Anamaya, New Delhi, 2006.

54 G. Kummerlöwe and M. K. Beyer, Int. J. Mass Spectrom., 2005, 244, 84 .

55 S. M. Lang, T. M. Bernhardt, R. N. Barnett and U. Landman, ChemPhysChem, 2010, 11, 1570.

56 L. Drahos and K. Vekey, J. Mass Spectrom., 2001, 36, 237.

57 A. A. Shvartsburg, K. M. Ervin and J. H. Frederick, J. Chem. Phys., 1996, 104, 8458 .

58 H. Häkkinen, Chem. Soc. Rev., 2008, 37, 1847.

59 P. V. Nhat and M. T. Nguyen, Phys. Chem. Chem. Phys., 2011, 13, 16254.

60 Nguyen Ngoc Ha, private communication.

61 P. S. Bagus and G. Pacchioni, J. Phys.: Conf. Ser., 2008, 117, 012003.

62 G. Blyholder, J. Phys. Chem., 1964, 68, 2772.

$63 \mathrm{X} . \mathrm{Wu}, \mathrm{L}$. Senapati, S. K. Nayak, A. Selloni and M. Hajaligol, J. Chem. Phys., 2002, 117, 4010.

64 A. Fielicke, G. von Helden, G. Meijer, B. Simard and D. M. Rayner, J. Phys. Chem. B, 2005, 109, 23935.

65 D. Schooss, P. Weis, O. Hampe and M. M. Kappes, Philos. Trans. R. Soc. London, Ser. A, 2010, 368, 1211. 